\title{
Colorimetric Detection of Cobalt in Different Solvents by Using Their Solvatochromic Properties
}

\author{
Dhiraj Dutta ${ }^{1}$, Rama Dubey ${ }^{1 *}$, Sanjai Kumar Dwivedi ${ }^{1}$, Amrit Puzari ${ }^{2}$ \\ ${ }^{1}$ Defence Research Laboratory, Solmara, Tezpur-784001, Sonitpur, Assam, India \\ ${ }^{2}$ National Institute of Technology, Chumukedima, Dimapur-797103 Nagaland, India
}

\author{
DOI: $10.36348 /$ sjet.2020.v05i04.003 \\ | Received: 07.04.2020 | Accepted: 14.04.2020 | Published: 17.04.2020 \\ *Corresponding author: Rama Dubey
}

\section{Abstract}

Cobalt chloride solutions exhibit different colours in different solvents thus displaying solvatochromic behaviour. This study reports spectrophotometric investigation of solvatochromic behavior of cobalt chloride solutions in different polar protic and aprotic solvents. The results are discussed in correlation with solvent properties such as dielectric constant, hydrogen bonding ability of solvent, ratio between hydrocarbon chain length and number of polar groups. Spectrophotometric analysis of solutions was carried out to understand interaction between solvent and cobalt salt as well as probable molecular structure of salt-solvent complex. The results showed that most of the polar protic solvents displayed pink color and polar aprotic ones showed blue colour. When the results with a series of alcoholic solvents were compared it was found that colour is not only a function of hydrogen bonding ability of solvent but also depends on hydrocarbon chain length.

Index Headings: Solvatochromism, spectrophotometry, aprotic, protic, polar, solvent.

Copyright @ 2020: This is an open-access article distributed under the terms of the Creative Commons Attribution license which permits unrestricted
use, distribution, and reproduction in any medium for non-commercial use (NonCommercial, or CC-BY-NC) provided the original author and source
are credited.

\section{INTRODUCTION}

Cobalt chloride solvent systems have been a matter of interest and curiosity for the scientific community worldwide due to their colorful solvatochromic behavior. A number of investigators have studied the absorption spectra of cobalt chloride solutions in hydrochloric acid [1-4]. The focus of most of the studies was directed towards analysis of absorption bands and prediction of structure of coloured complexes. The absorption spectra of solutions of cobalt chloride, cobalt bromide and cobalt iodide in concentrated hydrochloric, hydrobromic and hydriodic acids was studied by Wallace R. Brode et al., [5]. The change in absorption spectrum of cobalt chloride in aqueous solution with increasing concentration of hydrochloric acid was studied by Albert Jackson et al., [6].

Katzin et al., carried out spectrophotometric studies of cobaltous chloride in different solvent systems [7]. He was the first researcher who used optical spectroscopic data to analyze cobalt salt structures. Fine and Trutia in subsequent studies revealed the presence of several types of complexes in cobalt chloride solvent systems [8,9]. The absorption spectra of cobalt chloride in concentrated perchlorate solution was studied by K. Mizutani et al., [10]. He mentioned that the colour change of cobalt chloride from pink to reddish violet on addition of large amount of sodium perchlorate was due to decrease of water activity caused by the added inert salt which favours the formation of chloro complexes. The colour of transition metal compounds particularly solvatochromic behavior of cobalt (II) chloride was studied by M. Raczko et al., [11]. Absorption spectra of $\mathrm{CoCl}_{2} /$ Acetone systems was again studied by A. Trutia et al., [12] Selective solvation of $\mathrm{Co}^{2+}$ in aqueous ethanol was studied by Hafiz ur Rehman [13] and behavior of cobalt cations in aqueous and alcoholic solutions of cobalt chloride hexahydrate was also investigated by P. Petkova et al., [14], Cobalt chloride based humidity sensor attached to sol-gel modified cellulosic material was studied by R. Tessadri et al., [15], Recently P. Zielonka et al., studied visualization of wood humidity using cobalt chloride during microwave drying [16]. They proposed a simple method using cobalt chloride solution which on drying changes its colour from transparent through light pink up to deep blue thus allowing for visualization of moisture content in wood sample. 
Hence it is observed that Cobalt chloride solutions have been extensively studied since nineteenth century for their colorful solvatochromic behavior and sensing property especially for their application as humidity sensor. However till date no such study has been carried out where cobalt chloride solvent interaction has been spectroscopically investigated with respect to solvent properties such as dielectric constant, hydrogen bonding ability of solvent especially ratio between hydrocarbon chain length and number of polar hydroxyl groups. Hence spectrophotometric analysis of cobalt chloride solutions in different types of protic and aprotic solvents with varying chain lengths and number of polar hydroxyl groups was carried out to understand interaction between solvent and cobalt salt as well as resulting solvatochromic response.

\section{MATERIALS AND METHODS}

Cobalt salt $\left(\mathrm{CoCl}_{2} \cdot 6 \mathrm{H}_{2} \mathrm{O}\right)$ was supplied by Aldrich and was used as received. Spectroscopic grade solvents (HPLC grade Fluka) used in the study were of highest available purity. Deionized water and borosil glasswares were used for preparation of solutions. UVVisible spectra were recorded by using instrument Analytikjena SPECORD 205 in the wavelength range 190-1100nm. A $50 \mathrm{~nm} / \mathrm{sec}$ scan speed and $1 \mathrm{~nm}$ recording steps were used. All samples were measured in a $1 \mathrm{~cm}$ path length quartz cuvette.

The cobalt salt was directly dissolved in $5 \mathrm{ml}$ of each solvent and the developed colour was recorded and spectra of solutions were measured by using UV-Vis spectrophotometer.

\section{RESULTS AND DISCUSSION}

Table-1 shows details of the solvents properties used in the study such as molecular formula, molecular weight, boiling point, density, water solubility and dielectric constant. The color of cobalt chloride solutions in each solvent is also mentioned. It is observed that cobalt chloride solutions displayed different colors in different solvents as shown in Fig-1. In addition to well reported two colors i.e. blue in acetone and pink in water some mixed colors were also observed. In this study two different categories of solvents were selected. Chloroform, acetonitrile, DMF, NMP and acetone being polar aprotic whereas methanol, ethanol, isopropanol, butanol, ethylene glycol, diethylene glycol, glycerol and water being polar protic. From Fig-1 it is observed that all the polar aprotic solvents showed blue colour, but few polar protic solvents i.e. isopropanol, butanol and diethylene glycol also showed blue color. Ethanol and chloroform showed pink colour with a slight bluish tinge. Rest of the solutions showed pink colour.

It has been reported in previous studies that cobalt chloride in aqueous solutions exist in the form of $\left.\left[\mathrm{Co}\left(\mathrm{H}_{2} \mathrm{O}\right)_{6}\right]^{2+}\right]$ having octahedral configuration and displaying pink colour which consists of a $\mathrm{Co}^{2+}$ ion surrounded by six water molecules in an octahedral arrangement as shown in Fig-2a. The electronegative oxygen atoms are positioned toward the positively charged $\mathrm{Co}^{2+}$ ion. On the other hand in DMF or acetone solutions the configuration is tetrahedral as shown in Fig-2b due to the presence of $\left[\mathrm{CoCl}_{4}\right]^{2-}$ ions exhibiting blue color. The equilibrium can be shifted from octahedral pink to tetrahedral blue by adding either $\mathrm{HCl}$ or chloride salts to aqueous solutions of cobalt chloride or in reverse direction that is from tetrahedral blue to octahedral pink by adding water as shown by equations 1 and 2 below:

$$
\begin{aligned}
& \left.\left[\mathrm{Co}\left(\mathrm{H}_{2} \mathrm{O}\right)_{6}\right]^{2+}\right] \text { (pink) } \rightleftharpoons\left[\mathrm{CoCl}_{4}\right]^{2-}(\text { blue }) \ldots \ldots \ldots \ldots \ldots \ldots \ldots \ldots \\
& \left.\left[\mathrm{Co}\left(\mathrm{H}_{2} \mathrm{O}\right)_{6}\right]^{2+}\right](\text { pink })+4 \mathrm{Cl}^{-} \rightleftharpoons\left[\mathrm{CoCl}_{4}\right]^{2-}(\text { blue })+6 \mathrm{H}_{2} \mathrm{O}
\end{aligned}
$$

Table-1: Solvent properties, colour and absorbance of $\mathrm{CoCl}_{2}$ solutions

\begin{tabular}{|c|c|c|c|c|c|c|c|c|c|}
\hline $\begin{array}{l}\text { S.L } \\
\text { No }\end{array}$ & Solvent & Formula & $\begin{array}{l}\text { Molecular } \\
\text { weight }\end{array}$ & $\begin{array}{l}\text { Boiling } \\
\text { point } \\
\left({ }^{0} \mathrm{C}\right)\end{array}$ & $\begin{array}{l}\text { Density } \\
(\mathrm{g} / \mathrm{ml})\end{array}$ & $\begin{array}{l}\text { Solubility } \\
\text { in } \mathrm{H}_{2} \mathrm{O} \\
(\mathrm{g} / \mathbf{1 0 0 g})\end{array}$ & $\begin{array}{l}\text { Dielectric } \\
\text { constant }\end{array}$ & Colour & $\begin{array}{l}\text { UV-Vis } \\
\text { Abs } \\
(\mathrm{nm})\end{array}$ \\
\hline 1. & Chloroform & $\mathrm{CHCI}_{3}$ & 119.38 & 61.7 & 1.498 & 0.795 & 4.81 & $\begin{array}{l}\text { Bluish } \\
\text { pink }\end{array}$ & $\begin{array}{l}520 \\
670\end{array}$ \\
\hline 2. & $\begin{array}{l}\text { Acetonitrile } \\
(\mathrm{MeCN})\end{array}$ & $\mathrm{CH}_{3} \mathrm{C}=\mathrm{N}$ & 41.05 & 81.16 & 0.786 & Miscible & 37.5 & Blue & $\begin{array}{l}590 \\
680\end{array}$ \\
\hline 3. & $\begin{array}{l}\text { Dimethyformam } \\
\text { i-de (DMF) }\end{array}$ & $\mathrm{H}-\mathrm{C}(=\mathrm{O}) \mathrm{N}\left(\mathrm{CH}_{3}\right)_{2}$ & 73.09 & 153 & 0.944 & Miscible & 36.7 & Blue & $\begin{array}{l}610 \\
670 \\
\end{array}$ \\
\hline 4. & $\begin{array}{l}\text { N-methyl -2- } \\
\text { pyrrolidinone } \\
\text { (NMP) }\end{array}$ & $\mathrm{CH}_{5} \mathrm{H}_{9} \mathrm{NO}$ & 99.13 & 202 & 1.033 & 10 & 32 & Blue & $\begin{array}{l}580 \\
660\end{array}$ \\
\hline 5. & Methanol & $\mathrm{CH}_{3} \mathrm{OH}$ & 32.04 & 64.6 & 0.791 & Miscible & 32.6 & $\begin{array}{l}\text { Light } \\
\text { pink }\end{array}$ & 520 \\
\hline 6. & Ethanol & $\mathrm{CH}_{3} \mathrm{CH}_{2} \mathrm{OH}$ & 46.07 & 78.5 & 0.789 & Miscible & 24.6 & Pink & 520 \\
\hline 7. & Butanol & $\mathrm{CH}_{3} \mathrm{CH}_{2} \mathrm{CH}_{2} \mathrm{CH}_{2} \mathrm{OH}$ & 74.12 & 117.6 & 0.81 & 6.3 & 17.8 & Blue & 670 \\
\hline 8. & Isopropanol & $\mathrm{CH}_{3}-\mathrm{CH}(-\mathrm{OH})-\mathrm{CH}_{3}$ & 88.15 & 82.4 & 0.785 & Miscible & 18.3 & Blue & $\begin{array}{l}570 \\
610 \\
660 \\
\end{array}$ \\
\hline
\end{tabular}


Dhiraj Dutta et al., Saudi J Eng Technol, April, 2020; 5(4): 144-149

\begin{tabular}{|l|l|l|l|l|l|l|l|l|l|}
\hline \hline 9. & Ethylene glycol & $\mathrm{HOCH}_{2} \mathrm{CH}_{2} \mathrm{OH}$ & 62.07 & 195 & 1.115 & Miscible & 37.7 & $\begin{array}{l}\text { Light } \\
\text { pink }\end{array}$ & 525 \\
\hline 10. & $\begin{array}{l}\text { Diethylene } \\
\text { glycol }\end{array}$ & $\mathrm{C}_{4} \mathrm{H}_{10} \mathrm{O}_{3}$ & 106.12 & 245 & 1.118 & 10 & 31.7 & Blue & $\begin{array}{l}550 \\
590 \\
680\end{array}$ \\
\hline 11. & Glycerol & $\mathrm{C}_{3} \mathrm{H}_{8} \mathrm{O}_{3}$ & 92.09 & 290 & 1.261 & Miscible & 42.5 & Pink & 525 \\
\hline 12. & Acetone & $\mathrm{C}_{3} \mathrm{H}_{6} \mathrm{O}$ & 58.08 & 56.2 & 0.786 & Miscible & 20.7 & Blue & 590 \\
& & & & & & 78.54 & $\begin{array}{l}\text { Light } \\
\text { pink }\end{array}$ & 520 \\
\hline 13. & Water & $\mathrm{H}-\mathrm{O}-\mathrm{H}$ & 18.02 & 100 & 0.998 & - & & & \\
\hline
\end{tabular}

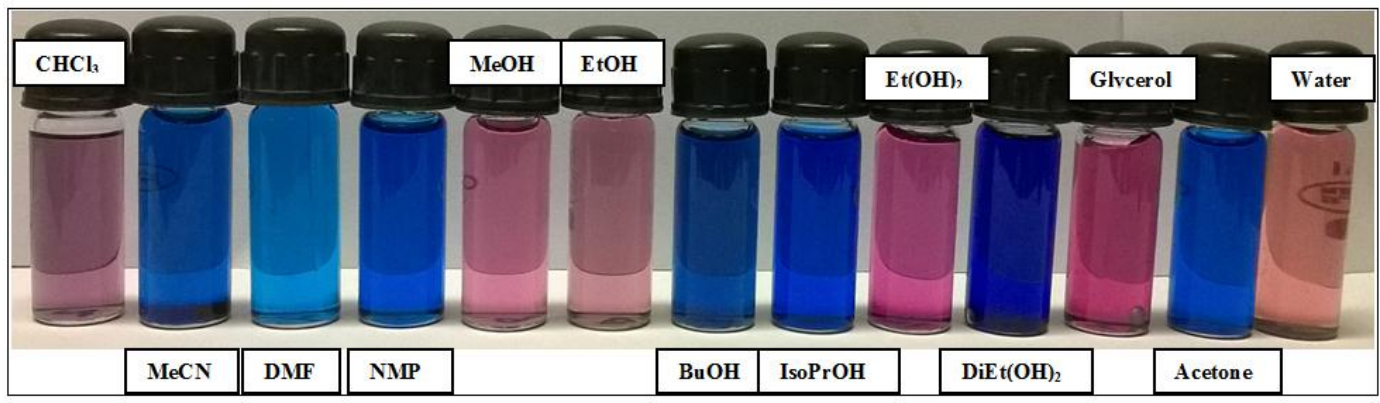

Fig-1: Colors of cobalt chloride solutions in different solvents

\section{UV-Vis Spectral Results}

The UV-Vis spectroscopic absorption bands of different cobalt chloride solutions are mentioned in Table-1. The absorption spectra of cobalt chloride solutions in polar aprotic solvents as acetonitrile, DMF, NMP and acetone displaying blue colour showed two absorption bands at 580-610nm and 660-700nm. Slight shifts in the peak positions were observed depending on the nature of solvent as noticed in the UV-Vis absorption spectrum of DMF and acetone shown in Fig 3 and 4 respectively. In DMF, two peaks one small at $610 \mathrm{~nm}$ and one broad at $670 \mathrm{~nm}$ is observed. Acetone system also shows multiple peaks from 590 to $695 \mathrm{~nm}$ range with broadening of peaks. Similar type of spectra of $\mathrm{CoCl}_{2}$ /Acetone systems were reported by A. Trutia et al., [9] where it was stated that acetone acts as a ligand due to oxygen atom and forms complex with $\mathrm{CoCl}_{2}$ showing absorption peaks in same region. On the other hand methanol, ethylene glycol, glycerol and water, showed pink color as shown in Fig-1. UV-Vis spectra of methanol and water are shown in Fig 5 and 6. Both solutions showed one very strong absorption band at $520-525 \mathrm{~nm}$. When small molecular size solvents such as water and methanol is used as a solvent, $\mathrm{CoCl}_{2}$ complexes with six total molecules to form pink octahedral complex ion. Strong solvation of $\mathrm{Co}^{2+}$ by water makes it difficult to form tetrahedral complex in aqueous solution. But ethylene glycol and glycerol also displayed pink colour and similar absorption band at 530nm observed for glycerol (Fig-7) proves that although bigger in molecular size compared to water and methanol but these two solvents are also able to form octahedral complexes. This result shows that in these two cases steric factors are overpowered by ion solvent interaction. This may be due to the presence of two and three hydroxyl groups respectively leading to greater chances for hydrogen bonding. Chloroform and ethanol solutions displayed pink color with slight bluish tinge (Fig-1). The UV-Vis absorption spectrum of $\mathrm{CHCl}_{3}$ solution is shown in Fig 8 which shows absorption spectra at $520 \mathrm{~nm}$ with a small hump at $670 \mathrm{~nm}$. The appearance of additional small hump shows partial formation of tetrahedral complex structures also in addition to formation of octahedral structures which is in correlation with slight bluish tinge in their solutions.

The solutions for large alcoholic solvents as isopropanol, butanol, diethylene glycol etc showed several peaks in the range of $500-700 \mathrm{~nm}$. With these alcohols it is observed that tetrahedral complex formation is preferred (blue color) rather than octahedral (pink color) to minimize repulsive forces and steric hinderance. Hence it can be stated that here steric factors play a dominant role in comparison to ion solvent interaction.

One of the important solvent property is dielectric constant $\left(\varepsilon^{\prime}\right)$, which is related to polarity of solvent. Higher the $\varepsilon^{\prime}$ of any solvent higher the polarity. Generally high $\varepsilon^{\prime}$ solvents like water, dissolves inorganic salts due to solvation of ions by $\mathrm{H}^{+}$and $\mathrm{OH}^{-}$ ions. From the Table $\mathrm{I}$ it is observed that only $\varepsilon^{\prime}$ is not the deciding parameter for color of $\mathrm{CoCl}_{2}$ solvent systems, as it is clearly seen that solvents having nearly similar $\varepsilon^{\prime}\left\{\mathrm{CH}_{3} \mathrm{CN}(37.5)\right.$, ethylene glycol (37.7) \& $\mathrm{CH}_{3} \mathrm{OH}$ (32.6), Diethylene glycol (31.7), NMP (32)\} showed different colours of $\mathrm{CoCl}_{2}$ solutions.

In addition to this observation, a very interesting phenomenon has also been observed where butanol a primary alcohol with 4 carbon atoms and one hydroxyl functional group shows blue colour whereas glycerol comparatively bulky triol with three carbon atoms and three hydroxyl functional groups showed pink colour. Similar phenomenon has been observed 
Dhiraj Dutta et al., Saudi J Eng Technol, April, 2020; 5(4): 144-149

with ethanol and ethylene glycol. Here both solvent molecules possess two carbon atoms but ethylene glycol with one extra hydroxyl group compared to ethanol showed pink colour in comparison to ethanol which showed bluish pink colour. The UV-Vis spectra of ethanol and ethylene glycol also show similarities with spectra of complexes having a mixture of both octahedral and tetrahedral complexes as well as only octahedral complexes respectively.

These observations show that number of polar hydroxyl groups plays a major role in deciding configurational structure of $\mathrm{CoCl}_{2}$-solvent complex system as well as color generated. More the number of polar $\mathrm{OH}$ groups more the probability of formation of octahedral complexes irrespective of other solvent properties.

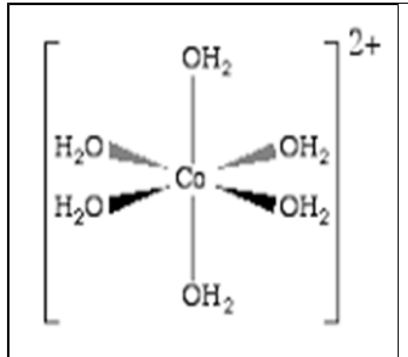

(a)

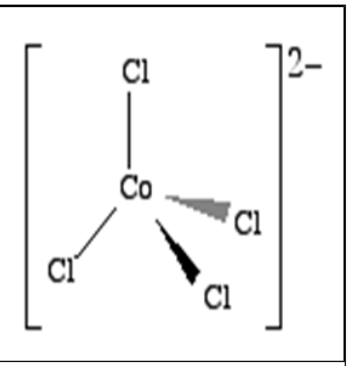

(b)
Fig-2(a): Octahedral configuration of cobalt hexahydrate ion and (b) Tetrahedral configuration of cobalt tetrachloride ion

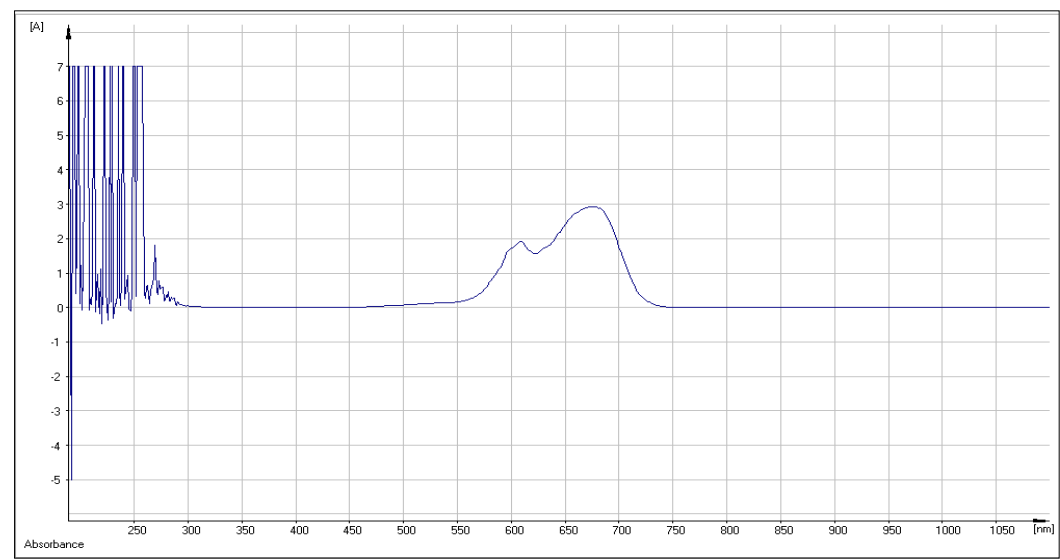

Fig-3: Absorption spectrum of blue colored $\mathrm{CoCl}_{2}$-DMF complex

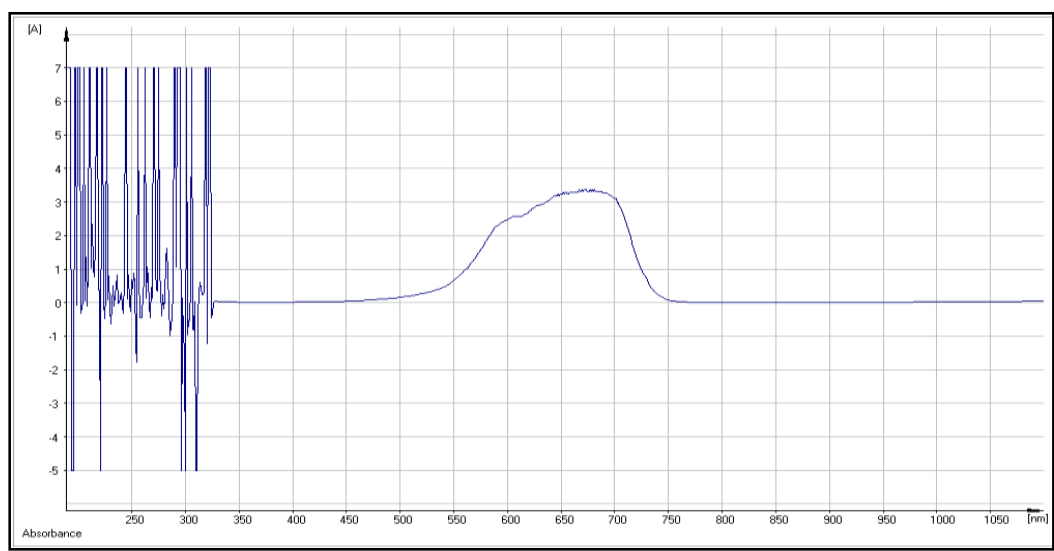

Fig-4: Absorption spectrum of blue colored $\mathrm{CoCl}_{2}$-acetone complex

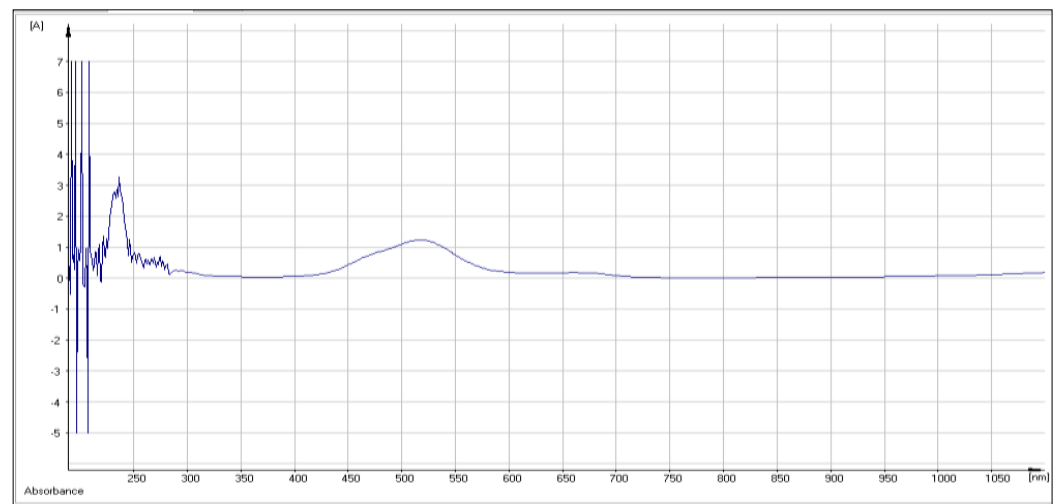

Fig-5: Absorption spectrum of pink colored $\mathrm{CoCl}_{2}$-methanol complex 


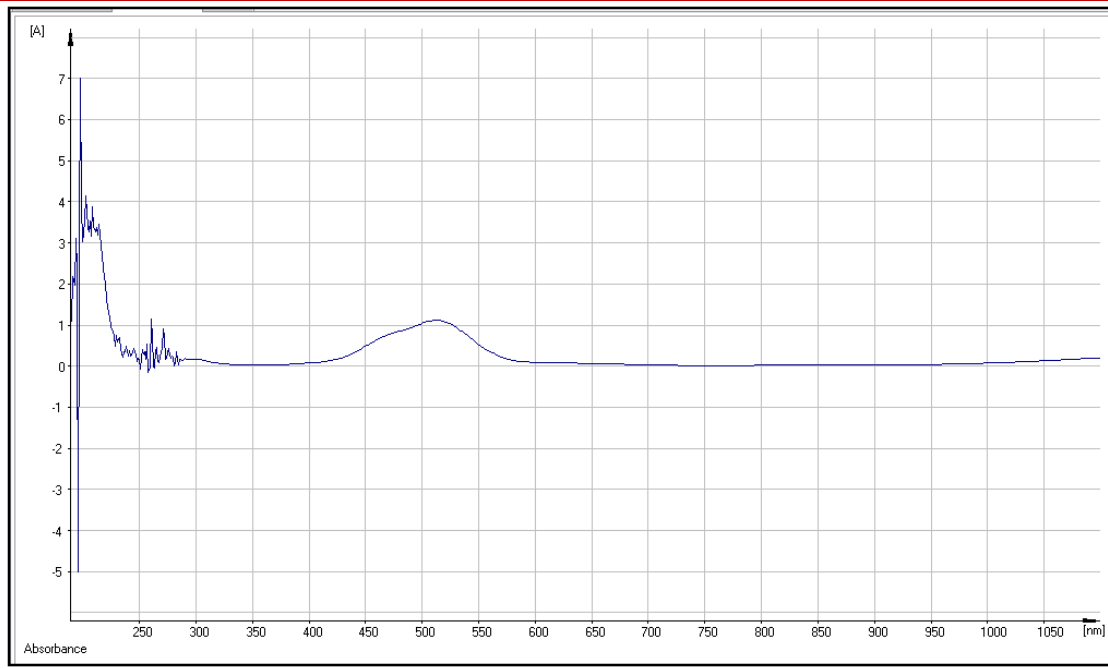

Fig-6: Absorption spectrum of pink colored $\mathrm{CoCl}_{2}$-water complex

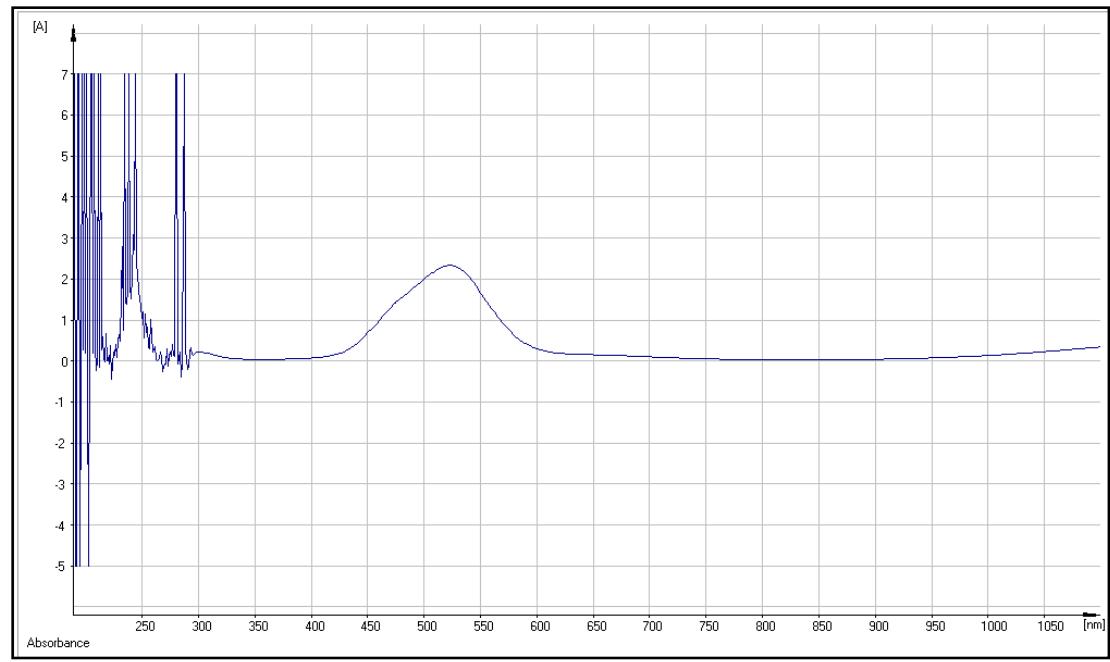

Fig-7: Absorption spectrum of pink colored $\mathrm{CoCl}_{2}$-glycerol complex

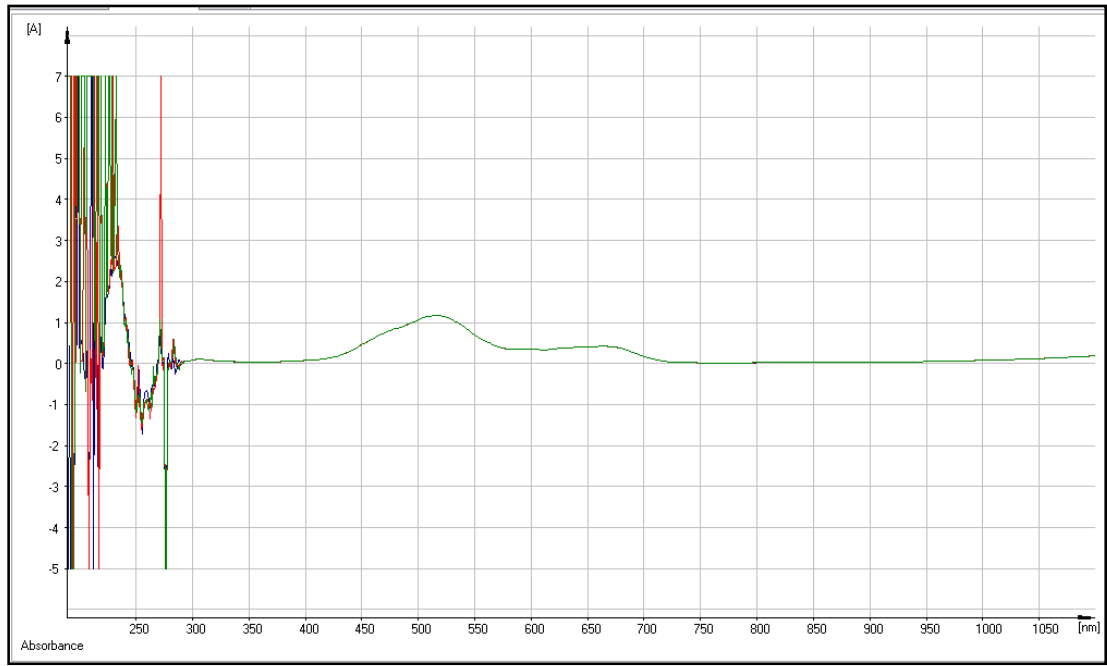

Fig-8: Absorption spectrum of bluish pink colored $\mathrm{CoCl}_{2}-\mathrm{CHCl}_{3}$ complex

\section{CONCLUSION}

In the present work, spectrophotometric analysis of solvatochromic behavior of cobalt chloride solutions in different polar protic and aprotic solvents was carried out by using UV-Vis spectroscopy. The results showed that most of the polar protic solvents displayed pink color and polar aprotic ones showed blue colour. The dielectric constant of solvents does not play major role in deciding the configuration and hence color of $\mathrm{CoCl}_{2}$-solvent complex system. When the results 
Dhiraj Dutta et al., Saudi J Eng Technol, April, 2020; 5(4): 144-149

with a series of alcoholic solvents with increasing chain length, branching and number of hydroxyl functional groups were compared it was found that colour is not only a function of hydrogen bonding ability of solvent due to the presence of polar hydroxyl groups but also depends on hydrocarbon chain length. Less the hydrocarbon chain length and more the number of hydroxyl groups, higher the probability of formation of pink octahedral complex and vice versa.

\section{REFERENCES}

1. Russell, W. J. (1881). Proceedings of the Royal Society of London, 32:258.

2. Hartley, W. N. (1903). XLV.-On colour changes observed in some cobalt salts. Journal of the Chemical Society, Transactions, 83, 401-405.

3. Jones, H. C., Getman, F. H., Bassett, H. P., McMaster, L., \& Uhler, H. S. (1907). Hydrates in aqueous solution. American Chemical Journal, 37:126.

4. Hill, R., \& Howell, O. R. (1924). LXXXI. Crystal structure and absorption spectra.-The cobaltous compounds. The London, Edinburgh, and Dublin Philosophical Magazine and Journal of Science, 48(287), 833-847.

5. Brode, W. R., \& Morton, R. A. (1928). The absorption spectra of solutions of cobalt chloride, cobalt bromide, and cobalt iodide in concentrated hydrochloric, hydrobromic, and hydriodic acids. Proceedings of the Royal Society of London. Series A, Containing Papers of a Mathematical and Physical Character, 120(784), 21-33.

6. Howell, O. R., \& Jackson, A. (1933). The change in the absorption spectrum of cobalt chloride in aqueous solution with increasing concentration of hydrochloric acid. Proceedings of the Royal Society of London. Series A, Containing Papers of a Mathematical and Physical Character, 142(847), 587-597.
7. Katzin, L. I., \& Gebert, E. (1950). Spectrophotometric Studies of Cobaltous Chloride1. Journal of the American Chemical Society, 72(12), 5464-5471.

8. Fine, D. A. (1962). Halide complexes of cobalt (II) in acetone solution. Journal of the American Chemical Society, 84(7), 1139-1144.

9. Trutia, A., \& Musa, M. (1966). Absorption spectra of divalent cobalt halides in ethanol and acetone. Revue Roumaine de Chimie, 11(8), 927.

10. Mizutani, K., \& Sone, K. (1967). Absorption Spectra of Cobalt (II) Chloride in concentrated perchlorate solutions. Zeitschrift für anorganische und allgemeine Chemie, 350(3-4), 216-224.

11. Bartecki, A., Tíczaĺ, T., \& Raczko, M. (1991). The color of transition metal compounds. II. Solvatochromism of Cobalt (II) chloride. Spectroscopy letters, 24(4), 559-575.

12. Stanescu, G., \& Trutia, A. (2005). On absorption spectra of $\mathrm{CoCl} 2 /$ acetone systems. Journal of optoelectronics and advanced materials, 7(2), 1009-1015.

13. Phonphuak, N. (2013). Effects of additive on the physical and thermal conductivity of fired clay brick. Journal of Chemical Science and Technology, 2(1), 95-99.

14. Petkova, P., \& Nedkov, V. (2013). Behavior of $\mathrm{Co} 2+$ cations in the aqueous and alcoholic solution of $\mathrm{CoCl} 2$. 6H2O. Acta Physica Polonica A, 123(2), 207-208.

15. Schramm, C., Kitzke, A., \& Tessadri, R. (2017). Cobalt chloride-based humidity sensor attached to sol-gel modified cellulosic material. Cellulose Chemistry and Technology, 51:273.

16. Zielonka, P., Jarzabek, W. A., Ksiazka, P., \& Dolowy, K. (2015). Annals of Warsaw University of Life Sciences-SGGW, Forestry and Wood Technology, 92:489. 